\title{
Duas abordagens artroscópicas para a articulação escapulo umeral no cão
}

\author{
Two arthroscopic approaches for the shoulder joint in dog
}

\author{
Julia Maria Matera' Angelica Cecilia Tatarunas ${ }^{\text {II }}$
}

\section{RESUMO}

O objetivo deste trabalho foi estudar em cadáveres de cães a exeqüibilidade do exame das estruturas intraarticulares através de duas diferentes abordagens artroscópicas da articulação escápulo-umeral. As articulações constituíram dois grupos: (A) o portal artroscópico foi estabelecido cranial e o portal instrumental caudal ao processo acromial; (B) o portal artroscópico foi confeccionado caudal e o portal instrumental cranial ao processo acromial. Durante o exame, procurou-se avaliar a possibilidade de visibilização concomitante com o toque através de sonda nas estruturas intra-articulares: cartilagem da cabeça do úmero (cranial, media e caudal), cavidade glenóide, tendão do músculo bíceps braquial, tendão do músculo subescapular, ligamento glenoumeral medial e lateral e bolsa articular caudal. As estruturas localizadas na porção cranial e média da articulação foram mais bem examinadas pela abordagem artroscópica realizada no grupo $B$, enquanto que aquelas estruturas situadas na porção média e caudal da articulação foram mais bem acessadas pela técnica utilizada no grupo A. Em nenhuma das abordagens, o ligamento glenoumeral lateral foi satisfatoriamente examinado.

Palavras-chave: artroscopia, canina, articulação do ombro.

\section{ABSTRACT}

This research was aimed at studing in dog corpses the feasibility of the exam of the intrarticular structures by using two different arthroscopic shoulder approaches. The joints were assembled in two groups: (A) the arthroscopic portal was established cranially and the instrumental portal caudally to the acromial process; (B) the arthroscopic portal was established caudally and the instrumental portal cranially to the acromial process. At the time of the exam the possibility of arthroscopic visualization concurrently with the touch with the probe of the intra articular structures was evaluated: humeral head cartilage (cranial, midlle and caudal), glenoid cavity, brachial biceps muscle tendon, subscapularis muscle tendon, medial and lateral glenohumeral ligament and caudal joint pouch. The intra articular structures situated in the cranial and middle side of the joint were better examined by approaching used in B group. On the other hand the structures localized in the caudal and middle portions of the joint were better inspected by approaching used in A group. However the lateral glenohumeral ligament was not completely checked neither using the A group approach nor using the B group approach.

Key words: arthroscopy, canine, shoulder joint.

\section{INTRODUÇÃO}

A artroscopia é uma modalidade relativamente nova dentro da ortopedia canina e, tal qual no homem (JACKSON, 2000), o estudo da articulação escápulo-umeral (AEU) apresentou o seu desenvolvimento mais tardio em relação à articulação do joelho, cujos conceitos de abordagem e diagnóstico já estão estabelecidos (PERSON, 1986; PERSON, 1989). O exame artroscópico permite a visibilização direta da cartilagem, da membrana sinovial, dos tendões e ligamentos intra-articulares sob iluminação e magnificação da imagem, dentro de um ambiente natural da articulação (BARDET, 1995; BARDET, 1998; MCCARTHY, 1999; TOMLINSON, 2001; JOHNSON; HULSE, 2002; BEALE et. al., 2003).

PERSON, em 1986, fez o primeiro estudo sobre a artroscopia da AEU, descrevendo três portais:

'Departamento de Cirurgia, Faculdade de Medicina Veterinária e Zootecnia, Universidade de São Paulo (FMVZ/USP). Rua Orlando Marques de Paiva, 87, 05508-900, Cidade Universitária, São Paulo, SP, Brasil. E-mail: materajm@usp.br. *Autor para correspondência. 
cranial à porção acromial do músculo deltóide e dorsal ao tubérculo maior; sobre o sulco intertubercular, em nível do ligamento umeral transverso e 1 a $2 \mathrm{~cm}$ caudal e 1 a 2cm distal ao acrômio. Posteriormente, GORING \& PRICE (1987) confeccionaram o portal entre as duas porções do músculo deltóide, cerca de $2 \mathrm{~cm}$ distal ao acrômio, e descreveram as estruturas intra-articulares observadas. VAN RYSSEN et al. (1993), por sua vez, estabeleceram os primórdios da cirurgia artroscópica desta articulação no cão, ao avaliarem a possibilidade de triangulação através da confecção concomitante de dois portais, artroscópico e instrumental, ambos distais ao processo do acrômio.

MCCARTHY, em 1999, descreveu a utilização do portal artroscópico situado no espaço entre o músculo deltóide e o tubérculo maior do úmero. MARTINI et al. (2002) propuseram técnica confeccionando dois portais, um cranial ao ligamento glenoumeral lateral e outro caudal, os quais foram invertidos em sua função de portal artroscópico e instrumental de acordo com a região a ser tratada.

Apesar da descrição de diferentes posições anatômicas para a confecção dos portais artroscópico e instrumental para a AEU no cão (GORING; PRICE, 1987; MARTINI et al., 2002; MCCARTHY, 1999; PERSON, 1986; PERSON, 1989; VAN RYSSEN et al., 1993), não foram especificadas a qualidade do exame das estruturas intra-articulares com concomitante visibilização e toque pelo instrumental. Propõe-se, portanto, neste trabalho, estudar em cadáveres de cães a exeqüibilidade do exame das estruturas intraarticulares da AEU através de duas abordagens distintas.

\section{MATERIAL E MÉTODOS}

Foram utilizadas 24 articulações escápuloumerais (AEUs) oriundas de 12 cadáveres de cães que foram a óbito no Hospital Veterinário da Faculdade de Medicina Veterinária e Zootecnia da Universidade de São Paulo. As articulações constituíram dois grupos, quanto à localização dos portais artroscópio e instrumental: grupo A - portal artroscópico cranial e portal instrumental caudal ao processo acromial; grupo B - portal artroscópico caudal e portal instrumental cranial ao processo acromial.

Durante o exame artroscópico, procurou-se avaliar as estruturas intra-articulares, ou seja, a sua visibilização artroscópica concomitantemente com o toque pela sonda. A qualidade do exame das estruturas intra-articulares foi graduada subjetivamente como: $(+)$ ótima, $(++)$ razoável ou $(+++)$ pobre.
As estruturas examinadas foram a cartilagem da cabeça do úmero (cranial, média e caudal), a cavidade glenóide, o tendão do músculo bíceps braquial, o tendão do músculo subescapular, o ligamento glenoumeral medial e lateral e a bolsa articular caudal. O exame iniciou-se na região proximal e prosseguiu para a porção caudal da articulação. As dificuldades e complicações ocorridas durante o exame artroscópico foram consideradas.

O material utilizado para a artroscopia consistiu de artroscópio $2,7 \mathrm{~mm}^{\mathrm{a}}, 30^{\circ}, 18 \mathrm{~cm}$, cânula de alto fluxo $4 \mathrm{~mm}^{\mathrm{a}}$, trocarte rombo ${ }^{\mathrm{a}}$ e sonda ${ }^{\mathrm{a}}$, fonte de luz ${ }^{\mathrm{a}}$ de xenônio $175 \mathrm{~W}$, cabo de fibra óptica ${ }^{\mathrm{a}}$, monitor colorido $^{\mathrm{a}}$, unidade de controle de câmera ${ }^{\mathrm{a}}$ e cabeça da câmera ${ }^{a}$. A documentação do exame artroscópico foi realizada através de videoimpressora ${ }^{\mathrm{b}} \mathrm{e} / \mathrm{ou}_{\text {filmagem }}^{\mathrm{c}}$.

Após tricotomia ampla da região das articulações AEUs, os cadáveres foram colocados em decúbito lateral com o membro a ser abordado por cima e a AEU em posição anatômica $\left(160^{\circ}\right)$. A área foi delimitada com campo cirúrgico. Foram identificados os pontos anatômicos de referência (acrômio, tuberosidade maior do úmero e tendão do músculo infra-espinhoso). Realizou-se artrocentese através da introdução de uma agulha hipodérmica 30x8 na porção lateral da articulação, perpendicular e entre o processo do acrômio e a cabeça do úmero. Uma seringa de $20 \mathrm{~mL}$ com solução salina isotônica foi acoplada à agulha e o líquido infundido até que se observasse resistência no êmbolo da seringa.

Para a confecção do portal artroscópico, realizou-se incisão cutânea de 1,0cm com lâmina de bisturi nº15 em local previamente determinado (grupo A ou B). Utilizou-se o trocarte rombo com a cânula para perfurar a cápsula articular e adentrar a articulação, concomitantemente com tração pela extremidade distal do membro. Na seqüência, o trocarte foi substituído pelo artroscópio. Um equipo acoplado a um frasco de solução salina isotônica de um litro foi conectado à cânula do artroscópio, servindo de via de influxo por gravidade.

Para a confecção do portal instrumental, utilizou-se a técnica da triangulação. Uma agulha hipodérmica 30x8 foi introduzida no local previamente determinado (Grupo A ou B). Após a sua localização pelo artroscópio, fez-se incisão de $1,0 \mathrm{~cm}$, com bisturi de lâmina nô15, adjacente ao ponto de entrada da agulha, iniciando na pele e posteriormente perfurando a cápsula articular. A perfuração da porção sinovial da cápsula articular foi monitorada pelo artroscópio. Através desta incisão, introduziu-se a sonda e iniciouse o exame da articulação.

Para o portal de drenagem, inicialmente, utilizou-se uma agulha hipodérmica 30x8 introduzida

Ciência Rural, v.37, n.2, mar-abr, 2007. 
cerca de $1 \mathrm{~cm}$ distal ao processo acromial. Posteriormente, o líquido infundido foi drenado pelos portais artroscópico e instrumental.

A qualidade de exame de cada estrutura intra-articular foi caracterizada como sendo ótima, razoável ou pobre. Foi considerada ótima quando a estrutura em questão pode ser completamente visibilizada e tocada com a sonda; razoável, quando pode ser visibilizada, porém não foi satisfatoriamente avaliada pelo toque com a sonda, e pobre quando a sua completa visibilização e exame com a sonda foram insatisfatórios.

\section{RESULTADOS}

O peso dos cadáveres variou de 12 a $50 \mathrm{~kg}$ (média = 27,2kg). Para realização da artrocentese inicial, foram utilizados de 8 a 30mL de solução fisiológica para distender a articulação, que variou de acordo com o porte do animal.

Foi difícil localizar o espaço intra-articular para a confecção do portal artroscópico em uma articulação $(8,4 \%)$ do grupo A e em duas $(16,7 \%)$ do grupo B e para a confecção do portal instrumental em uma articulação (8,4\%) do grupo A e em três (25\%) do grupo B. Houve dificuldade para a realização da triangulação durante a confecção do portal instrumental em quatro articulações (33,4\%), sendo uma do grupo A e três do grupo B. O deslocamento prematuro do artroscópio ocorreu de 1 a 3 vezes em 15 (62,5\%) articulações, sendo em sete do grupo A e em oito do grupo B; e do instrumental de 1 a 2 vezes, em duas articulações $(8,4 \%)$ do grupo A.
No grupo A, ocorreu lesão iatrogênica de cartilagem e ligamento em duas (16,7\%) articulações, cartilagem e cápsula articular em uma (8,4\%) e cartilagem em sete (58,4\%). No grupo B, houve lesão iatrogênica de cartilagem e ligamento em uma $(8,4 \%)$ e de cartilagem em oito (66,7\%) articulações. As lesões de cartilagem foram nas porções média e caudal da cabeça do úmero e na cavidade glenóide, e ocorreram durante a confecção dos portais. O ligamento glenoumeral medial e a bolsa articular caudal sofreram lesão iatrogênica durante a introdução do trocarte para a confecção do portal artroscópio. Os tipos de lesões que ocorreram na cartilagem e nos tecidos moles foram escoriações leves sem exposição do osso subcondral e perfurações puntiformes, respectivamente. Observou-se infiltração por solução salina dos tecidos moles periarticulares em oito $(66,7 \%)$ articulações do grupo A e em todas as articulações do grupo B (100\%).

Os resultados referentes à qualidade do exame das estruturas intra-articulares durante o procedimento artroscópico do grupo A encontram-se na tabela 1 . Neste grupo, a porção média e caudal da cabeça do úmero, da cavidade glenóide e do ligamento glenoumeral medial apresentaram ótima qualidade de exame em todas as articulações estudadas. De forma semelhante, a bolsa articular caudal foi observada em 11 articulações (91,7\%), a porção cranial da cabeça do úmero em oito $(66,7 \%)$, o tendão do músculo subescapular em sete $(58,4 \%)$, o tubérculo supraglenoidal em cinco $(41,7 \%)$, o ligamento glenoumeral lateral em duas $(16,7 \%)$ e o tendão do músculo bíceps-braquial em uma (8,4\%) articulação. A qualidade do exame artroscópico caracterizou-se como

Tabela 1 - Relação das estruturas intra-articulares das articulações escápulo-umerais do grupo A, quanto à qualidade de exame artroscópico por visualização e palpação. São Paulo, 2006.

\begin{tabular}{|c|c|c|c|c|c|c|c|c|c|c|}
\hline № & $\begin{array}{l}\text { Cabeça } \\
\text { Úmero- } \\
\text { Cranial }\end{array}$ & $\begin{array}{l}\text { Cabeça } \\
\text { Úmero- } \\
\text { Média }\end{array}$ & $\begin{array}{l}\text { Cabeça } \\
\text { Úmero } \\
\text { Caudal }\end{array}$ & $\begin{array}{l}\text { Cavidade } \\
\text { Glenóide }\end{array}$ & $\begin{array}{c}\text { Tubérculo } \\
\text { Supraglenoidal }\end{array}$ & $\begin{array}{l}\text { Tendão } \\
\text { Bíceps }\end{array}$ & $\begin{array}{c}\text { Ligamento } \\
\text { Glenoumeral } \\
\text { Medial }\end{array}$ & $\begin{array}{c}\text { Ligamento } \\
\text { Glenoumeral } \\
\text { Lateral }\end{array}$ & $\begin{array}{c}\text { Tendão } \\
\text { Músculo } \\
\text { Subescapular }\end{array}$ & $\begin{array}{c}\text { Bolsa } \\
\text { Articular } \\
\text { Caudal }\end{array}$ \\
\hline $1 \mathrm{D}$ & + & + & + & + & ++ & ++ & + & +++ & + & + \\
\hline $2 \mathrm{D}$ & + & + & + & + & + & ++ & + & +++ & + & + \\
\hline $3 D$ & + & + & + & + & + & ++ & + & + & ++ & ++ \\
\hline $4 \mathrm{D}$ & ++ & + & + & + & ++ & ++ & + & +++ & + & + \\
\hline $5 E$ & + & + & + & + & +++ & ++ & + & +++ & ++ & + \\
\hline $6 \mathrm{E}$ & ++ & + & + & + & + & +++ & + & +++ & ++ & + \\
\hline $7 \mathrm{E}$ & ++ & + & + & + & ++ & +++ & + & +++ & +++ & + \\
\hline $8 D$ & + & + & + & + & ++ & ++ & + & + & + & + \\
\hline $9 \mathrm{E}$ & + & + & + & + & ++ & ++ & + & ++ & ++ & + \\
\hline $10 \mathrm{E}$ & + & + & + & + & + & ++ & + & ++ & + & + \\
\hline $11 \mathrm{D}$ & + & + & + & + & + & + & + & ++ & + & + \\
\hline $12 \mathrm{E}$ & ++ & + & + & + & +++ & +++ & + & +++ & + & + \\
\hline
\end{tabular}

№: Número articulação～D: Direito E: Esquerdo Qualidade de exame: ótima: + razoável: ++ pobre: +++. 
razoável através desta abordagem para a porção cranial da cabeça do úmero em quatro articulações $(33,4 \%)$, para o tubérculo supraglenoidal em cinco (41,7\%), para o tendão do músculo bíceps-braquial em oito (66,7\%), para o ligamento glenoumeral lateral em três (25\%), para o tendão do músculo subescapular em quatro $(33,4 \%)$ e para a bolsa articular caudal em uma articulação $(8,4 \%)$. Foi considerado pobre o exame do tubérculo supraglenoidal em duas articulações (16,7\%), do tendão do músculo bíceps braquial em três (25\%), do ligamento glenoumeral lateral em sete $(58,4 \%)$ e do tendão do músculo subescapular em uma $(8,4 \%)$.

Os resultados sobre a qualidade do exame das estruturas intra-articulares durante o procedimento artroscópico das articulações do grupo B encontramse na tabela 2. A visibilização da porção cranial da cabeça do úmero, bem como do tubérculo supraglenoidal, apresentaram ótima qualidade de exame em todas as articulações estudadas. De forma semelhante, foram observados o tendão do músculo bíceps braquial em 11 articulações (91,7\%), o ligamento glenoumeral medial, a cavidade glenóide e o tendão do músculo subescapular em 10 (83,4\%), a porção média da cabeça do úmero em 9 (75\%), a porção caudal da cabeça do úmero e o ligamento glenoumeral lateral em $5(41,7 \%)$ e a bolsa articular caudal em uma articulação (8,4\%). Ainda, esta abordagem permitiu caracterizar o exame artroscópico como razoável para a porção média e caudal da cabeça do úmero em 3 (25\%) e 7 (58,4\%) articulações, respectivamente; cavidade glenóide em 3 (25\%), tendão do músculo bíceps braquial em uma (8,4\%), ligamento glenoumeral medial em duas (16,7\%), tendão do músculo subescapular em duas (16,7\%) e bolsa articular caudal em 5 articulações (41,7\%). Foi considerada pobre a qualidade do exame do ligamento glenoumeral lateral em 7 (58,4\%) e da bolsa articular caudal em 6 articulações (50\%) por meio desta abordagem.

Durante o procedimento artroscópico, o movimento de extensão da articulação mostrou-se especialmente importante para visibilização do ligamento glenoumeral medial, do tendão do músculo subescapular e da cápsula articular, em ambos os grupos. O movimento de balonamento também foi relevante para visibilizar a bolsa articular caudal.

\section{DISCUSSÃO}

A pequena cavidade óptica com confinamento ósseo rígido, a complexidade de algumas articulações e a fragilidade dos instrumentos faz com que a artroscopia seja considerada a técnica endoscópica rígida de maior dificuldade na espécie canina (PERSON, 1986; VAN RYSSEN et al., 1993; MCCARTHY, 1999; VAN RYSSEN et al., 2003; BEALE et al., 2003). Portanto, algumas falhas técnicas, como dificuldade para a confecção dos portais, remoção acidental do artroscópio ou instrumental e lesão iatrogênica, são possíveis de ocorrer (PERSON, 1986; VAN RYSSEN et al., 1993), o que foi vivenciado em algumas articulações deste estudo. A AEU do cão é envolta por espessa massa muscular (VAN RYSSEN et al., 2003), o que dificulta a realização dos portais

Tabela 2 - Relação das estruturas intra-articulares das articulações escápulo-umerais do grupo B, quanto à qualidade de exame artroscópico por visualização e palpação. São Paulo, 2006.

\begin{tabular}{|c|c|c|c|c|c|c|c|c|c|c|}
\hline № & $\begin{array}{l}\text { Cabeça } \\
\text { Úmero- } \\
\text { Cranial }\end{array}$ & $\begin{array}{l}\text { Cabeça } \\
\text { Úmero- } \\
\text { Média }\end{array}$ & $\begin{array}{l}\text { Cabeça } \\
\text { Úmero } \\
\text { Caudal }\end{array}$ & $\begin{array}{l}\text { Cavidade } \\
\text { Glenóidel }\end{array}$ & $\begin{array}{c}\text { Tubérculo } \\
\text { Supraglenoidal }\end{array}$ & $\begin{array}{l}\text { Tendão } \\
\text { Bíceps }\end{array}$ & $\begin{array}{c}\text { Ligamento } \\
\text { Glenoumeral } \\
\text { Medial }\end{array}$ & $\begin{array}{c}\text { Ligamento } \\
\text { Glenoumeral } \\
\text { Lateral }\end{array}$ & $\begin{array}{c}\text { Tendão } \\
\text { Músculo } \\
\text { Subescapular }\end{array}$ & $\begin{array}{l}\text { Bolsa } \\
\text { Articular } \\
\text { Caudal }\end{array}$ \\
\hline $1 \mathrm{E}$ & + & + & + & + & + & + & + & +++ & + & ++ \\
\hline $2 \mathrm{E}$ & + & + & + & + & + & ++ & + & + & + & ++ \\
\hline $3 \mathrm{E}$ & + & + & + & + & + & + & + & + & ++ & + \\
\hline $4 \mathrm{E}$ & + & ++ & ++ & ++ & + & + & ++ & +++ & + & ++ \\
\hline $5 \mathrm{D}$ & + & ++ & ++ & ++ & + & + & + & +++ & + & +++ \\
\hline $6 \mathrm{D}$ & + & + & ++ & + & + & + & + & +++ & + & +++ \\
\hline 7D & + & ++ & ++ & + & + & + & + & + & + & ++ \\
\hline $8 \mathrm{E}$ & + & + & + & + & + & + & + & + & ++ & +++ \\
\hline $9 \mathrm{D}$ & + & + & ++ & + & + & + & + & +++ & + & +++ \\
\hline $10 \mathrm{D}$ & + & + & + & + & + & + & + & + & + & ++ \\
\hline $11 \mathrm{E}$ & + & + & ++ & + & + & + & + & +++ & + & +++ \\
\hline $12 \mathrm{D}$ & + & + & ++ & ++ & + & + & ++ & +++ & + & +++ \\
\hline
\end{tabular}

№: Número articulação D: Direito E: Esquerdo Qualidade de exame: ótima: + razoável: ++ pobre: +++

Ciência Rural, v.37, n.2, mar-abr, 2007. 
artroscópico e instrumental e conseqüentemente favorece a ocorrência de injúria principalmente da cartilagem articular durante a sua confecção.

BARDET(1995), ROCHAT(2001) e BEALE et al. (2003) sugerem a realização do portal instrumental pela técnica de triangulação, a fim de avaliar a adequabilidade da posição do portal previamente a sua confecção. O insucesso na localização da agulha pelo artroscópio durante a triangulação pode advir do fato de esta não possuir comprimento adequado e/ou de estar inserida muito próxima ao artroscópio, o que torna o ângulo de convergência (ângulo formado entre o artroscópio e a agulha) muito agudo, sendo que a extremidade da agulha atravessaria por cima ou por baixo do artroscópio, impedindo a sua visibilização (MCCARTHY, 1999; JOHNSON; HULSE, 2002; BEALE et al., 2003). Constatou-se, neste estudo, que a dificuldade na realização da triangulação ocorreu principalmente devido à maior proximidade entre o portal artroscópico e o instrumental, resultado da pequena dimensão da articulação e, não necessariamente, de falha técnica. Tal fato também colaborou para a remoção acidental do artroscópio durante a tentativa de triangulação para a visibilização da agulha.

A lesão iatrogênica de cartilagem durante a confecção dos portais é complicação transoperatória passível de ocorrer, tendo geralmente relação inversa à experiência do cirurgião (PERSON, 1986; ROCHAT, 2001; BEALE et al., 2003). No presente estudo, esta ocorreu principalmente durante a introdução do trocarte para a confecção do portal artroscópico, sendo de intensidade leve. Devido à não-observação de lesões de tecidos moles durante a realização de artroscopia desta articulação em casos clínicos (MATERA et al., 2005), tal qual relatado neste estudo, atribui-se a sua ocorrência à maior fragilidade dos ligamentos e da cápsula articular nos cadáveres, quando comparados aos do animal vivo.

A complicação de maior prevalência da artroscopia no cão é a infiltração nos tecidos moles periarticulares por líquido utilizado durante todo o procedimento cirúrgico (GORING \& PRICE, 1987; MCCARTHY, 1999; ROCHAT, 2001; TOMLINSON, 2001; JOHNSON \& HULSE, 2002; BEALE, 2003). Apesar de não trazer maiores conseqüências para o animal, pois geralmente o líquido é reabsorvido nas primeiras horas de pós-operatório, a infiltração periarticular pode dificultar ou até impedir o prosseguimento do exame (MCCARTHY, 1999; BEALE et al., 2003). Na articulação do ombro, a espessa musculatura circundante favorece a infiltração periarticular, que ocorreu na maioria das articulações estudadas, porém em nenhum dos animais impossibilitou a finalização do exame proposto. A infiltração periarticular foi minimizada quando foi evitada a infusão acidental de líquido fora da articulação à época da confecção do portal artroscópico, mantendose a viabilidade da via de drenagem durante todo o procedimento.

São sugeridas diferentes posições para o portal artroscópico e instrumental (PERSON, 1986; GORING; PRICE, 1987; PERSON, 1989; VAN RYSSEN et al., 1993; MCCARTHY, 1999; ROCHAT, 2001; MARTINI et al., 2002; BEALE et al., 2003), sendo preconizada por alguns autores a confecção do portal instrumental cranial ao processo do acrômio para a abordagem da porção cranial e a sua realização caudal a este para o acesso à porção caudal da articulação do ombro (MC CARTHY, 1999; MARTINI et al., 2002). Os resultados do presente estudo corroboram as afirmações acima, pois houve melhor qualidade de exame da bolsa articular caudal e da porção caudal da cabeça do úmero nas articulações do grupo A e melhor qualidade de exame das estruturas localizadas na porção cranial (tendão do músculo bíceps-braquial, do tubérculo supraglenoidal, da porção cranial da cabeça do úmero) nas articulações do grupo B. Já a porção medial da articulação, não mencionada pelos autores referidos, apresentou ótima qualidade de exame na maioria das articulações pertencentes a ambos os grupos, à exceção do tendão do músculo subescapular, que teve melhor qualidade de exame nas articulações do grupo B, quando comparado ao grupo A. Tal fato ocorreu devido à localização medial e cranial, dificultando o acesso com a sonda quando o portal instrumental foi confeccionado caudal ao processo acromial.

A qualidade de exame do ligamento glenoumeral lateral foi pobre na maioria das articulações estudadas em ambos os grupos. Foi difícil o exame da porção lateral da articulação a partir de portais laterais. Recentemente, foi descrita a utilização de um portal artroscópico cranial e medial para a visibilização das estruturas intra-articulares laterais (SPRANKLIN et al., 2006). Cabe ainda a avaliação da melhor combinação de portais artroscópico e instrumental para a visibilização e concomitante toque com a sonda do ligamento glenoumeral lateral.

\section{CONCLUSÕES}

A confecção do portal artroscópico em posição cranial ao processo acromial e do portal instrumental caudal a este favorece a visibilização concomitantemente com o toque das estruturas intraarticulares localizadas nas porções media e caudal da 
AEU. O portal artroscópico caudal ao processo acromial e o portal instrumental cranial a este permitem melhor qualidade de exame das estruturas localizadas nas porções cranial e média da AEU. O ligamento glenoumeral lateral não é satisfatoriamente examinado nas abordagens estudadas.

Lesões iatrogênicas, principalmente de cartilagem, são passíveis de ocorrer durante a artroscopia da articulação do ombro no cão.

\section{AGRADECIMENTOS}

À Fundação de Amparo à Pesquisa do Estado de São Paulo (FAPESP), pela bolsa de pós-doutorado 2004/002997 .

\section{FONTES DE AQUISIÇÃO}

${ }^{\mathrm{a}}$ Karl Storz GmbH \& Co, Tuttlingen, Alemanha.

${ }^{\mathrm{b}}$ Filmadora - Sony Corporation, EUA.

'Vídeo Printer - Sony Corporation, EUA.

\section{REFERÊNCIAS}

BARDET, J.F. Arthroscopie diagnostique de l’épaule chez le chien. Prat Méd Chirurg L’ Anim Comp, v.30, n.1, p.4754, 1995.

BARDET, J.F. Diagnosis of shoulder instability in dogs and cats: a retrospective study. J Am Anim Hosp Assoc, v.34, n.1, p.42-54, 1998

BEALE, B.S. et al. Small animal arthroscopy. Philadelphia: Saunders, 2003. 229p.

GORING, R.L.; PRICE, C. Artroscopical examination of the canine scapulohumeral joint. J Am Anim Hosp Assoc, v.23, n.5, p.551-555, 1987.

JACKSON, R.W. História da artroscopia. In: ANDREWS, J.R.; TIMMERMAN, L.A. Artroscopia diagnóstica e cirúrgica.
Rio de Janeiro: Revinter, 2000. p.3-6.

JOHNSON, A.L.; HULSE, D.A. Diseases of the joints. In: FOSSUM, T.W. Small animal surgery. 2.ed. St. Louis: Mosby, 2002. p.883-993.

MARTINI, F.M. et al. A simplified technique for diagnostic and surgical arthroscopy of the shoulder joint in the dog. J Sm Anim Pract, v.43, n.1, p.7-11, 2002.

MATERA, J.M. et al. O uso da artroscopia na osteocondrite dissecante da articulação do ombro. Braz J Vet Res Anim Sci, v.42, n.4, p.299-306, 2005.

MCCARTHY, T.C. Arthroscopy. In: FREEMAN, L.J. Veterinary endosurgery. Philadelphia: Mosby, 1999. p.237-250.

PERSON, M.W. Arthroscopy of the canine shoulder joint. Comp Cont Ed Pract Vet, v.8, n.8, p.537-548, 1986.

PERSON, M.W. Arthroscopic treatment of osteochondritis dissecans in the canine shoulder. Veterinary Surgery, v.18, n.3, p.175-189, 1989.

ROCHAT, M.C. Arthroscopy. Vet Clin North Am Sm Anim Pract, v.31, n.4, p.761-787, 2001.

SPRANKLIN, D. et al. Use of a standard lateral portal and establishement of a craniomedial portal for arthroscopic examination of the glenohumeral joint in normal dogs. In: WORLD VETERINARY ORTHOPEDIC CONGRESS, 2.; ANNUAL VETERINARY ORTHOPEDIC SOCIETY MEETING, 33., 2006, Keystone. Proceeding... Keystone: Veterinary Orthopedic Society, 2006. p.237.

TOMLINSON, J. Arthroscopy in dogs: basic principles. In: WORLD SMALL ANIMAL VETERINARY ASSOCIATION CONGRESS, 26., 2001, Vancouver. Proceedings... Vancouver: SOTAL, 2001. p.638-640.

VAN RYSSEN, B. et al. Arthroscopy of the shoulder joint in the dog. J Am Anim Hosp Assoc, v.29, n.2, p.101-105, 1993

VAN RYSSEN, B. et al. Small animal arthroscopy. In SLATTER, D. Textbook of small animal surgery. 3.ed. Philadelphia: Saunders, 2003. p.2285-2312. 